\title{
The hardships of families on parents with drug use
}

\author{
Ming-Hong Hsieh ${ }^{1}$, Chiao-Yu Yang ${ }^{2}$ and Hui-Ching $\mathrm{Wu}^{3 *}$ \\ ${ }^{1}$ Department of Psychiatry, School of Medicine, Chung Shan Medical University, Taiwan \\ ${ }^{2}$ School of Social Welfare, University at Albany, SUNY, NY, USA \\ ${ }^{3}$ Department of Social Work, National Taiwan University, Taipei, Taiwan
}

Most individuals with illicit drug use/misuse have family and significant others who are affected by the user regardless of whether they have become estranged or remain close and even provide caring roles [1]. The co-occurrence of parental drug use (PDU) and problematic parenting is recognized as a major public health and social concern. PDU affects both the physical and psychological wellbeing of family members resulting in at higher risk of exposure to antisocial and criminal behaviors from the drug use/misuse such as poor mental health, unemployment, deprivation, marital problems, domestic violence, child abuse and inadequate parental capacity would occur [2].

Both in Western and Eastern countries, the families of child development on PDU were attended. According to the 2012 National Survey on Drug Use, an estimated 7.5 million children, or $10.5 \%$ of the population 17 years of age and younger, live with at least one parent who abuses drugs or alcohol [3] and nearly two thirds of adults enrolled in substance abuse treatment programs [4]. In Taiwan, the numbers of child abuse/neglect of PDU are slightly growth. According to the 2017 National Statistic of Child and Youth Protection, 11.9\% of parents of child abuse/neglect involves in substance use [5]. Of the few international studies available, the Illinois study [6] showed that these children of PDU had a very high level of behavioral problems, traumatization, and youth welfare needs. They are highly represented in the population of children in protective custody, having been removed from their primary caregivers due to abuse or neglect [7]. Salo and Flykt [8] found that children of PDU are at risk for poor cognitive, social, and emotional development.

Dawe, Harnett, Rendalls, \& Staiger, [9] applied part of an ecological system model [10] to the field of substance abuse. The studies indicated that many parents are dependent more than one kind of substances (e.g., alcohol, Methamphetamine) [11]. Substantial evidence suggests that drug users often have concurrent mental health issues, such as depression and anxiety [12], live in dysfunctional families (e.g., high rates of inter-parental conflict, limited parenting support from partners), and are socially isolated from the community [13]. Living dependently on the kinds of substance and mental health conditions, the parent would impact the well-being of child development.

Reviewing the pathways of conceptualizing the connections between PDU and parenting difficulties from multiple angles within the ecological system [14] and based on anecdotal experience, an Eastern conceptual framework was developed as (Figure 1) [14,15]. It is a reciprocal relationship in which PDU compromises effective parenting and the child behavioral difficulties that may cause parents to cope with frustrations by turning to DU [14]. The impact factors of PDU included the psychological distress, co-occurring disorders, emotional management, parenting knowledge and preoccupation of

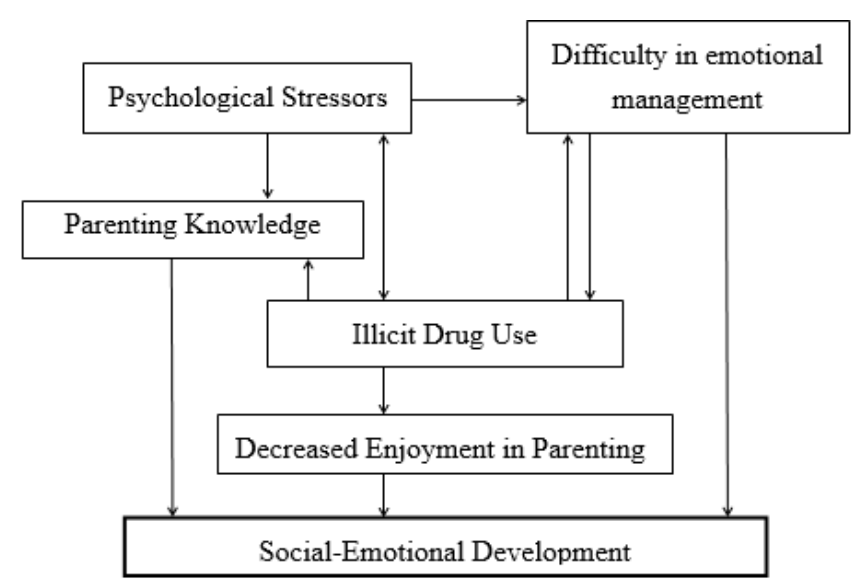

Figure 1. An Revised Frameworks connecting to illicit drug use and Child SocialEmotional Development

DU seeking that would contribute to the ongoing risk for the children/ youth development [16].

Especially for Methentamine (Meth)-use parents have been identified as a particular user subgroup [17], particularly favored by women of child-bearing age [18] and sexually disinhibited effect of the substance [17]. Meth was viewed as an uprising issue globally [19] for its readily availability, inexpensive appetite suppressant and energy enhancer [20]. Meth-use families are identified as having multiple and complex socio-economic problems (e.g. unemployment, financial debt, incarceration), specifically a strong link with domestic violence [21]. Being a highly addictive psychoactive stimulant, Meth produces a powerful euphoria, followed by a "crash" that causes hopelessness, irritability, sleeplessness, anxiety, and aggression resulting from paranoia [22] - all of which can create significant risk of child abuse and neglect, conduct problems, ADHD, emotional distress and traumatization [23].

Parenting intervention programs decreased in child maltreatment risk when compared to medication maintenance program only, especially for those intervention groups with continuous care [15]. However, few family interventions strengthen the principles of family preservation, family function and parent-child interaction were invested

${ }^{\star}$ Correspondence to: Hui-Ching Wu, Department of Social Work, National Taiwan University, No. 1, Sec. 4, Roosevelt Road, Taipei, Taiwan, E-mail: hchingwu@ntu.edu.tw

Received: July 08, 2020; Accepted: July 20, 2020; Published: July 23, 2020 
and little is known about the quality of parenting in these families. Interventions suggest base on the principles of family preservation focusing family resilience and positive interaction between the PDU and their children. The parenting knowledge and skills utilized such as increased parental sensitivity, use of reinforcement and attention for appropriate behavior, and active involvement with a child, having a long history of effectiveness with normally developing, at-risk, or clinically diagnosed children [24] are essential. It would foster the abstinence and improve function within the families.

\section{Acknowledgements and disclosures}

This study was funded by the Ministry of Science and Technology (108-2410-I-002-MY2)

Drs. Ming-Hong Hsieh \& Hui-Ching $\mathrm{Wu}^{*}$, declare that they have no conflict of interest.

All procedures followed were in accordance with the ethical standards of the responsible committee on human experimentation (institutional and national) and with the Helsinki Declaration of 1975 , as revised in 2000 (5). Informed consent was obtained from all participants for being included in the study.

\section{Reference}

1. Akram Y, Copello A, Moore D (2014) Family-based interventions for substance misuse: a systematic review of systematic reviews - protocol. Syst Rev 3: 90. [Crossref]

2. Barnard M (2007) Drug Addiction and Families. Kingsley: London and Philadelphia.

3. Substance Abuse and Mental Health Services Administration (2013) The National Survey on Drug Use and Health report: Data spot-light. Rockville, MD: Substance Abuse and Mental Health Services Administration.

4. Niccols A, Milligan K, Smith A, Sword W, Thabane L, et al. (2012) Integrated programs for mothers with substance abuse issues and their children: a systematic review of studies reporting on child outcomes. Child abuse \& negl 36: 308-322. [Crossref]

5. Ministry of Health and Welfare (2018) The National Statistic of Child and Youth Protection.

6. Haight W, Ostler T, Black J, Kingery L (2009) Children of methamphetamine-involved families: The case of rural Illinois. Oxford, Oxford University Press: New York.

7. U.S. Department of Health and Human Services (2009) Parental substance use and the child welfare system: Bulletin for professionals.

8. Salo S, Flykt M (2013) The impact of parental addiction on child development. In N.E Suchman, M. Pajulo, \& L. M. Mayes (Edn). Parenting and substance abuse: Oxford University Press, New York. pp. 195-210.
9. Dawe S, Harnett P, Rendalls V, Staiger P (2003) Improving family functioning and child outcome in methadone maintained families: The parents under pressure programme. Drug Alcohol Rev 22: 299-307. [Crossref]

10. Bronfenbrenner U (1979) The ecology of human development. Cambridge, MA: Harvard University Press.

11. Hall MT, Wilfong J, Huebner RA, Posze L, Willauer T (2016) Medication-assisted treatment improves child permanency outcomes for opioid-using families in the child welfare system. $J$ Subst Abuse Treat 71: 63-67.

12. Hans SL, Bernsrein VJ, Henson LG (1999) The role of psychopathology in the parenting of drug-dependent women. Dev Psychopathol 11: 957-977. [Crossref]

13. Dawe S, Harnett P, Newman L, Krabman P (2008) Improving family functioning in high risk families: The parents under pressure program. Aust Nz J Psychiat 42: A16.

14. Neger EN, Prinz RJ (2015) Interventions to address parenting and parental substance abuse: Conceptual and methodological considerations. Clin Psychol Rev 39, 71-82. [Crossref]

15. Peisch V, Sullivan AD, Breslend NL, Benoit R, Sigmon SC, et al. (2018) Parental Opioid Abuse: A Review of Child Outcomes, Parenting, and Parenting Interventions. J Child Fam Stud 1-18.

16. Whitaker RC, Orzol SM, Kahn RS (2006) Maternal mental health, substance use, and domestic violence in the year after delivery and subsequent behavior problems in children at age 3 years. Arch Gen Psychiatry 63: 551-560. [Crossref]

17. Milin S, Lotzin A, Degkwitz P, Verthein U, Schäfer I (2014) Amphetamin and methamphetamine groups of people with abusive consumption and starting points for preventive measures. Factual report. Center for Interdisciplinary Addiction Research (ZIS) at the University of Hamburg, Hamburg.

18. Hohman M, Oliver R, Wright W (2004) Methamphetamine abuse and manufacture: The child welfare response. Soc Work 49: 373-381. [Crossref]

19. United Nations Office on Drugs and Crime (2016) World drug report. New York.

20. Joe KA (1995) Ice is strong enough for a man but made for a woman. Crime, Law and Social Change 22: 269-289.

21. Cartier J, Farabee D, Prendergast ML (2006) Methamphetamine use, self-reported violent crime, and recidivism among offenders in California who abuse substances. $J$ interpers violence 21: 435-445. [Crossref]

22. Office of National Drug Control Policy (2010) Methamphetamine trends in the United States.

23. Parvaresh N, Mazhari S, Nazari-Noghabi M (2015) Frequency of Psychiatric Disorders in Children of Opioid or Methamphetamine-Dependent Parents. Addict Health 7: 140 148. [Crossref]

24. Kaminski JW, Claussen AH (2017) Evidence base update for psychosocial treatments for disruptive behaviors in children. J Clin Child Adolesc Psychol 46: 477-499. [Crossref]

Copyright: (C2020 Hsieh MH. This is an open-access article distributed under the terms of the Creative Commons Attribution License, which permits unrestricted use, distribution, and reproduction in any medium, provided the original author and source are credited. 